\title{
Investigation of the effect of swimming programs on improving vocational relationships
}

\author{
Iman Nazerian $^{\mathrm{a}^{*}}$, Mohammad Reza Iravani ${ }^{\mathrm{b}}$ and Akram Soltani ${ }^{\mathrm{c}}$
}

${ }^{a}$ Department of Physical Education and Sport Science of Mobarakeh Branch, Islamic Azad University, Esfahan, Iran

${ }^{b}$ Department of Social Work, Islamic Azad University, Khomeinishahr Branch, Daneshjou Blvd, Iran

${ }^{c}$ Department of Human Science of Khomeinishahr Branch, Islamic Azad University, Daneshjou Blvd, Esfahan, Iran

\begin{tabular}{|c|c|}
\hline ARTICLEINGO & AB S TRACT \\
\hline $\begin{array}{l}\text { Article history: } \\
\text { Received September 1, } 2011 \\
\text { Received in Revised form } \\
\text { October, 22, } 2011 \\
\text { Accepted 24 September } 2011 \\
\text { Available online } \\
\text { 27 September 2011 } \\
\text { Keywords: } \\
\text { Recreational activities } \\
\text { Vocational relationships } \\
\text { Productivity } \\
\text { Efficiency } \\
\text { Swimming }\end{array}$ & $\begin{array}{l}\text { Recreational activities play important role on workers' health conditions and improve people's } \\
\text { creativity. Steel industry is one of industries, where workers mainly face with hard working } \\
\text { conditions. There are various techniques to help human resources increase their potentials such } \\
\text { as providing recreational centers, athletic facilities, etc. In this paper, we study the impact of } \\
\text { regular swimming exercises on improving the efficiency of employees in management level in } \\
\text { a steel complex unit called Mobarakeh Steel Complex. In this company, there were about } 85 \\
\text { middle level managers and supervisors and the proposed study selects } 30 \text { people, randomly and } \\
\text { divides them into two equal groups. In the first stage of the study, questionnaire of vocational } \\
\text { relation are distributed among the participants of this study and some important factors, which } \\
\text { could improve vocational relationships are measured. Next, the experimental groups are invited } \\
\text { to take part in some selective aerobic programs for } 8 \text { weeks and } 3 \text { sessions per week and } 1 \text { hour } \\
\text { and } 15 \text { minutes per session, regularly. Finally, we repeat the same experiments after the aerobic } \\
\text { programs end and compare the results with the first one. The preliminary results indicate that } \\
\text { the routine swimming programs have increased people self confidence, creativity and working } \\
\text { group skills. }\end{array}$ \\
\hline
\end{tabular}

(C) 2012 Growing Science Ltd. All rights reserved.

\section{Introduction}

There are many evidences, which indicate that routine exercise programs could have various positive impacts on people's creativity, innovation and self-confidence. Exercise could increase people's general health care, lower blood pressure and improve the sense of teamwork. There is no doubt that human capital is the most precious value of any organization. Workers are considered as the main source for creating value in all industries especially the ones where wage is the main component of the cost of final product. Human capital is sometimes called as core competence for many organizations since many value added decisions are made through human capital's creativity and innovation.

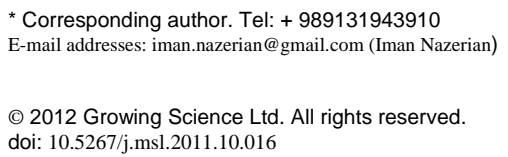


There are many organizations trying to develop their human capital as much as possible and motivate employees in order to face challenges. Therefore, employees are considered as the key success at different levels in terms of productivity, competitiveness not only through the knowledge they can contribute but also by the value they could add to client relationships, product quality, and so forth. Sobhanallahi and Shayan (1998) studied the effect of cell-based team-work in productivity improvement at a manufacturing firm. They explained the effects of the prevailing behavioral system, which was influenced by cultural and environmental circumstances, impact of history, geographical situation, state of technology and employees' attitude. A team-work effort was arranged around a cellular manufacturing exercise to explain an effective change in the performance and existing circumstances. Scott et al. (2003) presented an aerobic exercise physiology in a professional rugby union team. Hambley. (2007) presented a virtual team leadership by studying the impacts of leadership effects and communication medium on team interaction styles and outcomes.

The employee is a valuable asset for the companies and in some cases, the employees are the only true competitive advantage for a company (Storey \& Sisson, 1993; Delery \& Doty, 1996; Bolwijn \& Kumpe, 1996; Becker \& Gerhart, 1996).

They investigated on how it could lie within the framework of general employee management policies. In their study, a sample of staff who worked for ten enterprises was selected and questionnaire was distributed among them. The study revealed that sport at companies could take on multiple functions and forms of structures in situ, events, company sporting associations, sponsorship, and so forth. Sport has various functions and they are often correlated and integrated into human resources management in terms of training and motivational tools, or both internal and external communication policies. Besides, they could also contribute to the social policy of the company. They concluded that sport in business could be a contributor to company's identity by highlighting intangible and human resources.

Coulson et al. (2008) studied the impact of exercising at work on the performance of the employee. In their study, they showed that that workday exercise could improve white-collar workers' mood and self-reported performance on days when they exercise at work for several days when they do not. There are clear implications not only for employee's healthcare, but also for competitive advantage and motivation by increasing opportunities for exercising at work. Thompson (1997) presented a case study on how one small company started a health care program for employees in an attempt to avoid higher health-care expenditures and to improve employee morale. The paper explained the process of developing the program, and its success in detail to increase employees' ability to work better.

Chikuji et al. (1999) studied the effects of low intensity aerobic training on the physiological indexes and the quality of life in middle-aged white-collar workers. They studied the effect of prolonged whole-body low-intensity exercise on blood lipids, skeletal muscle adaptations and aerobic fitness. They selected seven male subjects and asked them to complete a 32-day crossing of the Greenland icecap on cross-country skies and they measured before and after this arm or leg cranking on two separate days. They also executed some biopsies from arm and leg muscle, and venous blood. They concluded that the exercise could improve the people's performance since an improved blood lipid profile and thus metabolic fitness appeared after prolonged low-intensity training and this occurred despite a decreased aerobic fitness and an unchanged arm and leg muscle hormone-sensitive lipase activity (Helge et al., 2008)

Einspruch (1996) explained how challenge of providing rehabilitative services at relatively low price could help companies increase their productivities. They study also explains that if there is a link between the company' objectives and customer satisfaction, it is imperative to evaluate quality or customer satisfaction in the context of the patient's experience and described the quality function deployment system and how it could lead to a better understanding of the customer's needs and wants. In this paper, we study the impact of providing exercise facilities on improving the efficiency 
of employees in management level in the biggest steel producers in Iran called Mobarakeh Steel Complex.

The proposed study of this paper considers 85 middle level managers \& supervisors, and selects 30 people, randomly and divides them into two equal groups. In the first stage of the study, questionnaire of vocational relation are distributed among the participants of our experiment and we measure some important factors, which could improve vocational relationships. Next, the experimental groups are invited to take part in some selective aerobic programs for 8 weeks and 3 sessions per week and 1 hour and 15 minutes per session, regularly. Finally, we repeat the same experiments after the swimming programs end and compare the results with the first one. This organization of this paper first explains details of the implementation of our experiments in section 2 and then we perform statistical analysis on the proposed method in section 3. Finally, concluding remarks are given at the end to summarize the contribution of this paper.

\section{Research method}

The aim of the study is to investigate of the effects of selected swimming programs on improving vocational relationships of managers in Mobarakeh Steel Complex (MSC). MSC is Iran's second biggest steel plant, built in the mid-1990's. It is located $65 \mathrm{~km}$ southwest of a well-known city called Esfahan, near the city of Mobarakeh, and they both are located in Esfahan province, Iran. MSC is Iran's largest steel maker, and one of the largest industrial complexes operating in Iran. The company owns the successful football club, Sepahan. The team competes in Iran's top flight known as Persian Gulf League (PGL) and holds most of the records in the PGL under their belt. Sepahan is the latest champions of the PGL in 2010-11 seasons for the record third times in the ten-year PGL history. Sepahan is also the first and the only club to own the title of back-to-back seasons (2009-2010 and 2010-2011). As we can see, sport is one of the most important issues not only for promoting MSC's brand but also for contributing to Iranian society. The management team of the company was interested in contributing more to its human resources by expanding its recreational facilities in its different plants. The proposed study of this paper selected some well organized swimming programs to study their impacts on improving performance of employees in MSC firm. We first divided the participants into two groups and gathered some necessary information through questionnaire. The first group belongs to those who take part in our program and the second group belongs to the people who do not participate in our survey called control group. The information are collected from two groups once the selected group members finish their exercise. Fig. 1 shows details of different factors influencing employee's efficiency before and after they take part in swimming programs.

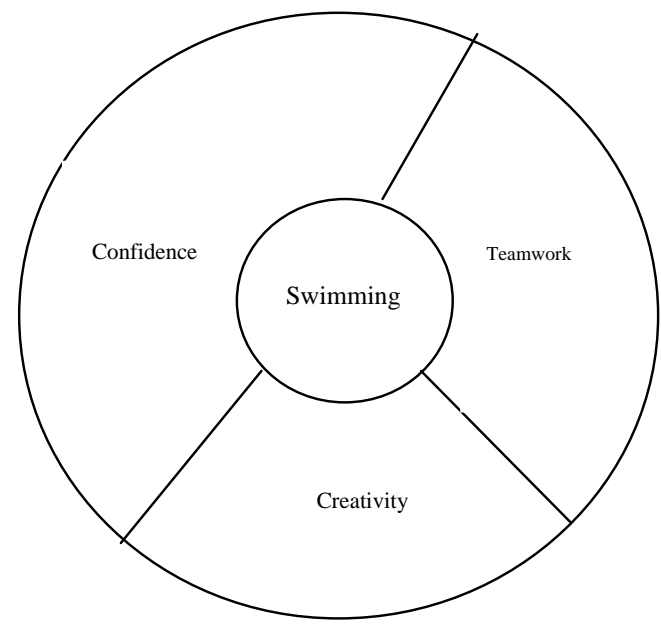

Fig. 1. Different components of having good relationship among workers 


\subsection{Statistical society}

The statistical society of this study includes all male intermediate grade of Mobarakeh steel who worked for the company during the fiscal year of 2007. Based on the statistics we gathered from human resource department, there were 85 people working as middle level management. Once the exercise program was announced, 200 individuals (men) were interested in participating in our survey. We have selected 30 people as our sampling and divided them into two groups of 15 people based on primary drug and completed testimonial form of the study.

\subsection{Method of performing research}

Selected programs of swimming included different activities presented by variable results due to physical capabilities and level of learning of the people who took part in our study. Practical sessions were regulated by level of heartbeat and in the first session, training swimming was noteworthy and so low severity of practices gradually were added to severity of exercises in the next session. In primary sessions heartbeat was maximum 75 beat/min and gradually in the last session reached to 140-160 beat/min and severity was additive from the first session to last session.

The first sessions were training course and last sessions were focused on more practice and improvement of skills. For all sessions we used various and attractive plays and entertainment programs. In other words, we assigned the first six sessions for training purposes, the next six sessions were assigned for practice and entertainment, and 12 sessions were also devoted for a combination of both with trains of swimming skills focused on breast crawl. The swimming program was designed for 8 weeks, every session took 1 hour and 15 minutes, and some respective experts provided some selected and extended swimming programs.

\subsection{Hypothesis}

There are two main hypothesis associated with the proposed study of this paper, which are as follows,

2.3.1. The employees who participate in swimming program are more cooperative in team-work activities.

\subsubsection{The employees who participate in swimming program are more creative.}

2.3.3. The employees who participate in swimming program are more cooperative.

2.3.4. The employees who participate in swimming program work with more confidence.

\subsubsection{The employees who participate in swimming program work are more efficient.}

In this study, we use different statistical observations such as F-value for measuring the effects of swimming programs on increasing employees' various characteristics. For each test, we compare the average numbers as well as standard deviation score of their performance before and after participating in such programs and compare them with some statistical test.

\section{The results}

In this section, we present the results of the information we gathered from both groups who either participated in our exercise program or not. 


\subsection{Validity and reliability of questionnaire}

In order to validate the results of our experiments we have used Cronbach Alpha (Cronbach, 1952) for small number of test results, which yielded $97 \%$. This number highly validates the results of our experiments. Next in order to detremine the reliability of our questionnaire, we gathered the mean and standard deviations scores of some five referees and compared them with the information we gathered from the participants using Candle correlation test. The result indicated a 87\% correlation between these two samples which is highly acceptable number and it confirms the reliability of our test.

\subsection{The first hypothesis: Swimming and teamwork}

Table 1 summarizes statistical results of our survey for the first hypothesis, which is relationship between swimming and teamwork.

\section{Table 1}

Relationship between teamwork and swimming

\begin{tabular}{lcccc}
\hline Item & F-statistic & P-value & Eta & Observed power \\
\hline Teamwork & 42.90 & 0.000 & 0.651 & 1.000 \\
\hline
\end{tabular}

As we can observe from the results of Table 1, there is a meaningful relationship between teamwork activities and swimming program. Table 2 shows the mean and standard deviation between control group and others. As we can observe, the average number has increased, substantially.

\section{Table 2}

The mean and standard deviation scores of pre and posttest for the first hypothesis

\begin{tabular}{lcc}
\hline Group & mean & Standard deviation \\
\hline Control & 21.89 & 0.982 \\
Experimental & 31.31 & 0.982 \\
\hline
\end{tabular}

\subsection{The second hypothesis: Swimming and creativity}

Table 3 summarizes statistical results of our survey for the second hypothesis, which is relationship between swimming and creativity.

\section{Table 3}

Relationship between creativity and swimming

\begin{tabular}{lcccc}
\hline Item & F-statistic & P-value & Eta & Observed power \\
\hline Teamwork & 41.68 & 0.000 & 0.644 & 1.000 \\
\hline
\end{tabular}

As we can observe from the results of Table 3, there is a meaningful relationship between creativity and swimming program. Table 4 shows the mean and standard deviation between control group and others. As we can observe, the average number has increased after employees took part in swimming programs, significantly.

\section{Table 4}

The mean and standard deviation scores of pre and posttest for the second hypothesis

\begin{tabular}{lcc}
\hline Group & mean & Standard deviation \\
\hline Control & 15.97 & 0.872 \\
Experimental & 24.22 & 0.872 \\
\hline
\end{tabular}




\subsection{The third hypothesis: Swimming and cooperation}

Table 5 summarizes statistical results of our survey for the third hypothesis, which is the relationship between swimming and cooperation.

\section{Table 5}

Relationship between cooperation and swimming

\begin{tabular}{lcccc}
\hline Item & F-statistic & P-value & Eta & Observed power \\
\hline Teamwork & 20.267 & 0.000 & 0.473 & 0.992 \\
\hline
\end{tabular}

As we can observe from the results of Table 3, there is a meaningful relationship between creativity and swimming program. Table 6 shows the mean and standard deviation between control group and others. As we can observe, employees seem to be more cooperative when they participate in swimming programs.

\section{Table 6}

The mean and standard deviation scores of pre and posttest for the third hypothesis

\begin{tabular}{lcc}
\hline Group & mean & Standard deviation \\
\hline Control & 12.31 & 0.928 \\
Experimental & 18.49 & 0.928 \\
\hline
\end{tabular}

\subsection{The fourth hypothesis: Swimming and confidence}

Table 7 summarizes statistical results of our survey for the fourth hypothesis, which is the relationship between swimming and self-confidence.

\section{Table 7}

Relationship between self-confidence and swimming

\begin{tabular}{lcccc}
\hline Item & F-statistic & P-value & Eta & Observed power \\
\hline Teamwork & 29.95 & 0.000 & 0.566 & 0.999 \\
\hline
\end{tabular}

As we can observe from the results of Table 7, there is a meaningful relationship between selfconfidence and swimming program. Table 8 shows the mean and standard deviation between control group and others. As we can observe, employees seem to have more self-confidence when they participate in swimming programs.

\section{Table 8}

The mean and standard deviation scores of pre and posttest for the fourth hypothesis

\begin{tabular}{lcc}
\hline Group & mean & Standard deviation \\
\hline Control & 14.252 & 0.744 \\
Experimental & 20.214 & 0.744 \\
\hline
\end{tabular}

\subsection{The fourth hypothesis: Swimming and efficiency}

Table 9 summarizes statistical results of our survey for the fourth hypothesis, which is the relationship between swimming and efficiency.

Table 9

Relationship between efficiency and swimming

\begin{tabular}{lcccc}
\hline Item & F-statistic & P-value & Eta & Observed power \\
\hline Teamwork & 85.383 & 0.000 & 0.788 & 1.000 \\
\hline
\end{tabular}


As we can observe from the results of Table 9, there is a meaningful relationship between efficiency and swimming program. Table 10 shows the mean and standard deviation between control group and others. As we can observe, employees seem to have more efficient when they are involved with swimming programs.

\section{Table 8}

The mean and standard deviation scores of pre and posttest for the fifth hypothesis

\begin{tabular}{lcc}
\hline Group & mean & Standard deviation \\
\hline Control & 19.63 & 0.557 \\
Experimental & 27.17 & 0.557 \\
\hline
\end{tabular}

The results of this survey emphasize the fact that a routine swimming exercise could improve healthcare and work performance.

\section{Conclusion}

In this paper, we have presented an empirical study to learn the effects of the swimming programs on improving the healthcare performance of middle level managers who worked for an steel industry unit in Iran. The proposed study divided the people into two groups and measured some data for both groups. Next, the study asked the second group to participate in an aerobic program and the tests were repeated for both groups after the program was terminated. We then compared the results and realized that there was meaningful difference between the healthcare conditions of the people who participated in our program compared with the people who did not. The proposed study of this paper would indicate that swimming programs play important role on increasing people's potential work. It can increase people's teamwork capabilities, improve sense of creativity and innovation and increase their efficiency.

\section{Acknowledgment}

The authors would like to thank MSC complex for providing extensive support to collect the necessary information of this survey. The authors would like to thank the anonymous referees for the constructive comments on earlier version of this paper, which enriched the content of the paper and made it more understandable.

\section{References}

Becker, B.E., \& Gerhart, B. (1996). The impact of human resource management on organizational performance: progress and prospects. Academy of Management Journal, 39(4), 779-801.

Bolwijn, P.T., \& Kumpe, T. (1996). About facts, fiction and forces in human resources management. Human Systems Management, 15(3), 161-72.

Chikuji, K., Motoyama, M., Ohto, H., Morita, T., Sunami, Y., Tanaka, M., \& Shindo, M. (1999). The effects of low intensity aerobic training on the physiological indexes and the quality of life in middle-aged white collar workers. Sangyo Eiseigaku Zasshi, 41(3), 63-71.

Coulson, J.C., McKenna, J., \& Field, M. (2008). Exercising at work and self-reported work performance. International Journal of Workplace Health Management, 1(3), 176-197.

Cronbach, L. J. (1951). Coefficient alpha and the internal structure of tests. Psychometrika, 16(3), 297-334.

Delery, J.E., \& Doty, D.H. (1996). Modes of theorizing in strategic human resource management: tests of universalistic, contingency and configurational performance predictions. Academy of Management Journal, 39(4), 802-35. 
Einspruch, E.M. (1996). Quality function deployment (QFD): application to rehabilitation services. International Journal of Health Care Quality Assurance, 9(3), 41-46.

Helge, J.W., Damsgaard, R., Overgaard, K., Andersen, J. L., Donsmark, M., Dyrskog, S.E., Hermansen, K., Saltin, B., \& Daugaard, J. R. (2008). Low-intensity training dissociates metabolic from aerobic fitness. Scandinavian Journal of Medicine \& Science in Sports, 18(1), 86-94.

Hambley, L.A., O’Neill, T.A., \& Kline, T.J.B. (2007). Virtual team leadership: The effects of leadership style and communication medium on team interaction styles and outcomes. Organizational Behavior and Human Decision Processes, 103(1), 1-20.

Scott, A.C., Roe, N., Coats, A.J.S., \& Piepoli, M.F. (2003). Aerobic exercise physiology in a professional rugby union team. International Journal of Cardiology, 87(2-3), 173-177.

Storey, J., \& Sisson, K. (1993). Managing Human Resources and Industrial Relations. Open University Press, Buckingham.

Sobhanallahi, A., \& Shayan, E. (1998). Effect of cell based team work in productivity improvement at a manufacturing company, 35(3-4), 451-454.

Thompson, J. (1997). Employee health programmes: a model designed for a local company. Journal of Workplace Learning, 9(2), 83-87. 